Revista Eletrônica em Gestão, Educação e Tecnologia Ambiental

REGET/UFSM (e-ISSN: 2236-1170).

\title{
RECUPERAÇÃO DE COBALTO DE BATERIAS ÍON-LÍTIO ATRAVÉS DE LIXIVIAÇÃO ÁCIDA E ELETRO-OBTENÇÃO
}

\author{
Camila Ottonelli Calgaro ${ }^{1}$, Jalusa Konzen Albiero ${ }^{1}$, \\ Lucas Meili ${ }^{1}$, Marcelo Barcellos da Rosa ${ }^{2}$, Daniel Bertuol. \\ 1 -Lapam - Laboratório de Processos Ambientais e Operações Unitárias - Departamento de Engenharia Química - \\ UFSM \\ 2- Lachem - Laboratório de Análises Químicas - Departamento de Química - UFSM
}

\section{Resumo}

O grande desenvolvimento tecnológico e o consumo significativo de baterias, destacandose as baterias de íon-lítio utilizadas em celulares, fazem com que estas se tornem rapidamente obsoletas, sendo necessário o desenvolvimento de processos eficientes de recuperação e reciclagem. Essas baterias usam grafite como eletrodo negativo e $\mathrm{LiCoO}_{2}$ Como eletrodo positivo. Esse material catódico é utilizado pela sua alta densidade de energia e facilidade de fabricação, porém, é de alto custo e as reservas mundiais de cobalto são limitadas. Visando a recuperação desses metais, foram realizados ensaios baseados nos processos hidrometalúrgicos de reciclagem, passando por etapas físicas e mecânicas de moagem e separação granulométrica, por processo químico de lixiviação e eletroquímico em uma célula de dois compartimentos separada por membrana aniônica. Dos primeiros obteve-se uma significativa separação física dos materiais de interesse e do processo eletroquímico obteve-se cobalto na forma de depósito sólido, a partir de soluções sintéticas de cobalto e lítio.

\section{Introdução}

O crescente avanço tecnológico tem propiciado um consumo significativo de aparelhos portáteis e consequentemente de baterias, dentre elas se destacam as baterias de íon-lítio utilizadas em celulares [1]. Proporcionalmente ao consumo, aumenta também o descarte destas baterias, sendo necessário o desenvolvimento de processos de recuperação e reciclagem. Atualmente no Brasil, o destino de pilhas e baterias é regulamentado pela Política Nacional de Resíduos Sólidos (PNRS), segundo esta, os fabricantes, importadores, distribuidores e comerciantes devem implementar e estruturar sistemas de logística reversa, de forma que os produtos sejam retornados após o uso pelo consumidor [2], dando-lhes assim, o destino adequado. No Estado do Rio Grande do Sul a Lei 11.187 proíbe a disposição de qualquer material contendo metal pesado junto com os resíduos sólidos municipais.

Estima-se que 3 bilhões de baterias são comercializadas por ano somente nos EUA, o que representa um faturamento de US\$ 2,5 bilhões. Na Europa cinco bilhões de baterias foram produzidas em 2000 [3]. No Japão estimasse que em torno de seis bilhões de baterias foram produzidas em 2004. No Brasil quase um bilhão de unidades são consumidas a cada ano [4].

Nos últimos anos as baterias de $\mathrm{NiMH}$ vem sendo continuamente substituídas pelas baterias de Íon-Lítio. Em 1992 as baterias de níquel-cádmio (NiCd) eram responsáveis por quase 100\% do mercado mundial de baterias portáteis, já em 1999 representavam somente 49\%. A substituição das baterias de $\mathrm{NiMH}$ ocorreu devido às novas baterias de ĺon-Lítio, além de 


\section{Revista Eletrônica em Gestão, Educação e Tecnologia Ambiental}

REGET/UFSM (e-ISSN: 2236-1170).

ambientalmente aceitáveis, apresentarem melhor performance isto é, maior densidade de energia.

Existem dois tipos de baterias Íon-Lítio, as primárias e as secundárias. As primárias usam lítio metálico como cátodo e não contêm nenhum metal tóxico; porém, há a possibilidade de fogo se o lítio metálico é exposto à umidade, fato que pode ocorrer em caso de corrosão do invólucro externo. As baterias secundárias (recarregáveis), por outro lado, não contém lítio metálico. A maioria dos sistemas Íon-Lítio usam um material igual LiXMA ${ }_{2}$ como eletrodo positivo e grafite como eletrodo negativo. Um material muito utilizado como cátodo é o LiCoO2, e como eletrólito é utilizado uma solvente orgânico, tóxico e inflamável, com substâncias como $\mathrm{LiClO}_{4}$, $\mathrm{LiBF}_{4} \mathrm{e} \mathrm{LiPF}$. Estas baterias são constituídas basicamente por: 5-20\% cobalto, 5-10\% níquel, 5-7\% lítio, 15\% substâncias químicas orgânicas e $7 \%$ plásticos, sendo que a composição que varia ligeiramente dependendo do fabricante [5].

As baterias de íon-lítio têm o seguinte princípio de funcionamento: a energia é armazenada pelo movimento dos íons de lítio do cátodo para o ânodo (processo de carga) ou vice-versa (processo de descarga) de acordo com a equação global [6]:

$$
\mathrm{LiCoO}_{2}+6 \mathrm{C} \leftrightarrow \mathrm{Li}_{(1-x)} \mathrm{CoO}_{2}+\mathrm{C}_{6} \mathrm{Li}_{x}
$$

$\mathrm{O}$ material catódico, $\mathrm{LiCoO}_{2}$, é utilizado pela sua alta densidade de energia e facilidade de fabricação, porém, é de alto custo e as reservas mundiais de cobalto são limitadas. Desta forma, a reciclagem dos metais presentes em baterias deve ser estudada, evitando-se assim a geração e consequente disposição de toneladas de resíduos perigosos. Este fato, associado ao valor econômico de metais como lítio, cobalto e cobre que estão presentes na composição destes resíduos, faz com que sejam avaliados processos eficientes de reciclagem. Portanto a reciclagem deste tipo de resíduo além de trazer ganhos em termos ambientais também pode trazer benefícios em termos econômicos.

Sucatas metálicas podem ser submetidas a diferentes processos químicos e físicos de reciclagem. Nos processos hidrometalúrgicos de reciclagem de baterias íon-Lítio, estas são submetidas a processos físicos de pré-tratamento como moagem e separação granulométrica de forma a separar o material ativo do cátodo e do ânodo dos demais materiais. Então estes materiais que constituem o cátodo passam por uma série de processos químicos, como a lixiviação ácida, onde o cobalto pode ser recuperado.

A eletro-obtenção é um importante método de se recuperar o cobalto e consiste em converter íons metálicos de cobalto dissolvidos em uma solução em depósitos sólidos cristalinos. Isso ocorre através da aplicação de uma diferença de potencial em uma célula eletroquímica, composta por um eletrodo positivo e um eletrodo negativo.

\section{Metodologia}

Os ensaios realizados basearam-se no processamento mecânico seguido de processos hidrometalúrgicos e eletroquímicos de reciclagem.

Primeiramente se realizou uma caracterização das baterias, conforme modelo e marca disponíveis. A amostra selecionada foi cominuída em um moinho de facas (Rone N-150) e o material obtido é submetido a uma etapa de separação granulométrica, utilizando peneiras de abertura entre $4,75 \mathrm{~mm}$ a 0,3 $\mathrm{mm}$. Isso é feito para a obtenção da fração de menor granulometria, que posteriormente será tratada por processos químicos (lixiviação e eletro-obtenção).

No processamento químico, os materiais particulados mais finamente divididos obtidos no processamento mecânico que constituem os materiais ativos do cátodo e do ânodo são 


\section{Revista Eletrônica em Gestão, Educação e Tecnologia Ambiental \\ REGET/UFSM (e-ISSN: 2236-1170).}

submetidos a diferentes testes de lixiviação. Inicialmente, água régia foi empregada numa relação de $1 \mathrm{~g}$ para $20 \mathrm{~mL}$, devido a grande capacidade da água régia esta foi considerada como extração de $100 \%$, então foi realizado outro teste com ácido sulfúrico $2 \mathrm{~mol} / \mathrm{L}$ na mesma relação de sólidolíquido e peróxido de hidrogênio $15 \mathrm{vol} \%$ [3]. Após uma filtração o líquido lixiviado é enviado para o processo eletroquímico. A composição dos lixiviados foi analisada por Espectroscopia de Absorção Atômica.

Na etapa eletroquímica: a eletro-obtenção é realizada em uma célula eletrolítica, composta por dois compartimentos, o anódico e o catódico, ambos com livre circulação do anólito e do católito, respectivamente, e separados por uma membrana aniônica (PCacid 60). A utilização da membrana visa um aumento da eficiência de corrente pela separação das reações catódicas e anódicas, já que o $\mathrm{pH}$ é mais facilmente controlado. $\mathrm{O}$ cátodo utilizado é de aço inoxidável de 10 $\mathrm{cm}^{2}$ e um ânodo de titânio revestido com uma liga de platina/irídio com $49 \mathrm{~cm}^{2}$. As soluções são re-circuladas por bombas centrífugas, com vazão de $3 \mathrm{~L} / \mathrm{min}$ em ambos os compartimentos. No compartimento anódico é utilizada uma solução de $\mathrm{Na}_{2} \mathrm{SO}_{4} 1 \mathrm{M}$. realizados

$\mathrm{Na}$ determinação das condições ótimas da eletro-obtenção diferentes ensaios foram

Estes ensaios realizados tiveram a duração de 2 horas e são feitos a partir de soluções sintéticas com as seguintes composições: com apenas $40 \mathrm{~g} / \mathrm{L}$ de cobalto e com $40 \mathrm{~g} / \mathrm{L}$ de cobalto mais $2,5 \mathrm{~g} / \mathrm{L}$ de lítio. A relação entre a concentração dos diferentes metais foi selecionada em função das concentrações encontradas em soluções reais. Nestes testes, foram investigados o efeito da variação da temperatura e pH sob a eficiência de corrente obtida.

Para a determinação da eficiência de corrente é necessário medir a quantidade de cobalto depositada no cátodo e a quantidade teórica de material que deveria ter se depositado. A massa do depósito é obtida pela diferença de peso do cátodo antes e depois de cada ensaio. Para assegurar que esta diferença de massa seja exclusivamente referente ao depósito, tanto o cátodo quanto o depósito foram enxaguados e então secados com um jato de ar para assegurar que não ficasse aderida nenhuma gota de solução. Enquanto que o depósito teórico é obtido pela Lei de Faraday e a carga elétrica q aplicada é medida pelo amperímetro no tempo de reação. A eficiência é então calculada através da comparação entre o depósito medido no ensaio e o calculado. Os depósitos são caracterizados por Microscopia Eletrônica de Varredura (MEV) e Energia Dispersiva de Raios-X (EDS).

$\mathrm{O}$ pH é determinado com auxílio de um pHmetro e mantido constante através da adição de soluções concentradas de soda cáustica e ácido sulfúrico. Este controle é realizado em um béquer onde uma bomba retirava a solução para enviá-la a célula, após circular na célula a solução retornava ao béquer onde era enviada novamente, num circuito fechado por 2 horas.

\section{Resultados e Discussão}

Com a realização da amostragem verificou-se a predominância de baterias da marca Nokia, especialmente do modelo Nokia BL-5C. Estas baterias apresentam uma massa média de 20,97 g e foram então utilizadas no processamento mecânico, devido a sua representatividade. 0 processamento mecânico consiste de moagem, juntamente com a posterior análise e separação granulométrica, compreendem o tratamento primário dado as baterias.

A Figura 1 apresenta o balanço de massa correspondente ao tratamento primário de 30 baterias, julgando as perdas que ocorreram na moagem, tanto as perdas mássicas como a perda 
Revista Eletrônica em Gestão, Educação e Tecnologia Ambiental

REGET/UFSM (e-ISSN: 2236-1170).

de solvente, que volatiliza quando a bateria é aberta. Além disso, o fluxograma da Figura 1 apresenta também as frações obtidas e suas respectivas quantidades mássicas.

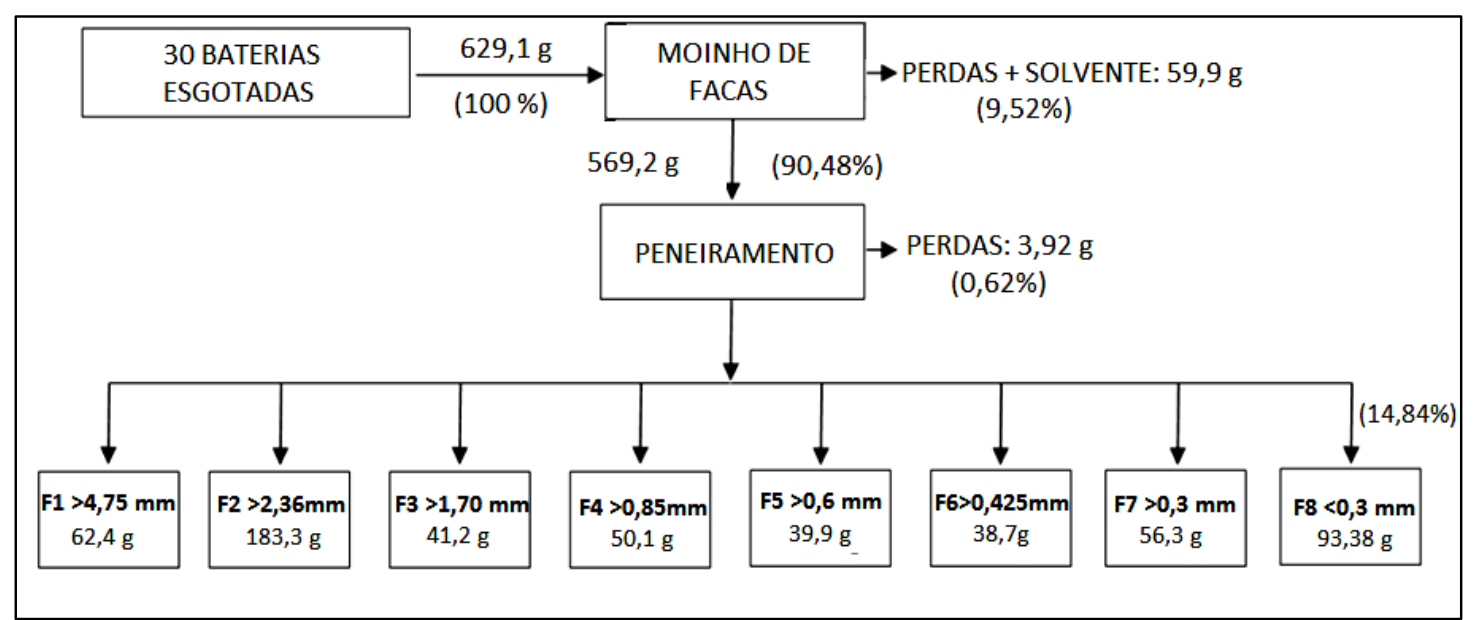

Figura 1: Balanço de massa do tratamento primário das baterias.

No balanço de massa (Figura 1) pode-se ver que a fração com maior quantidade de massa foi a de granulometria $>2,36 \mathrm{~mm}$ e que a fração de interesse, de menor granulometria $(<0.3 \mathrm{~mm})$, apresentou quantidade de massa inferior, porém significativa, igual a 93,38g. Essa grande quantidade de massa na segunda fração é um indicativo da possível presença de lítio e cobalto nas frações de maior granulometria, sendo relevante a realização de uma nova moagem e separação nas frações da bateria para uma maior recuperação dos metais.

A eficiência da separação granulométrica por peneiração pode ser analisada visualmente pela diferença de componentes presentes na fração $>4,75 \mathrm{~mm}$ e na fração $<0.3 \mathrm{~mm}$, apresentadas nas Figuras 2 e 3 respectivamente. Percebe-se que na Figura 1, estão presentes todos os componentes da bateria, destacando-se o cobre e o polímero do separador. Já na Figura 2, há apenas um pó constituído principalmente por grafite e $\mathrm{LiCoO}_{2}$, composto formado pelos metais a serem recuperados.

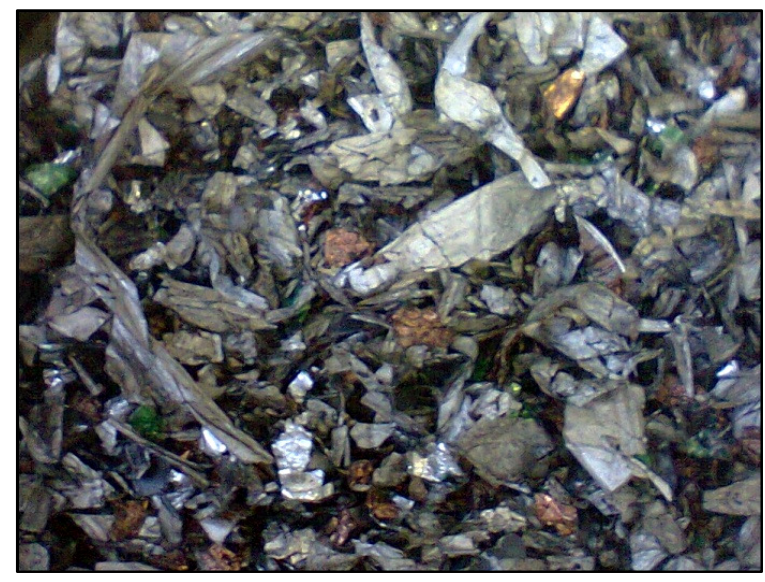

Figura 2: fração de granulometria $>4,75 \mathrm{~mm}$. 
Revista Eletrônica em Gestão, Educação e Tecnologia Ambiental

REGET/UFSM (e-ISSN: 2236-1170).

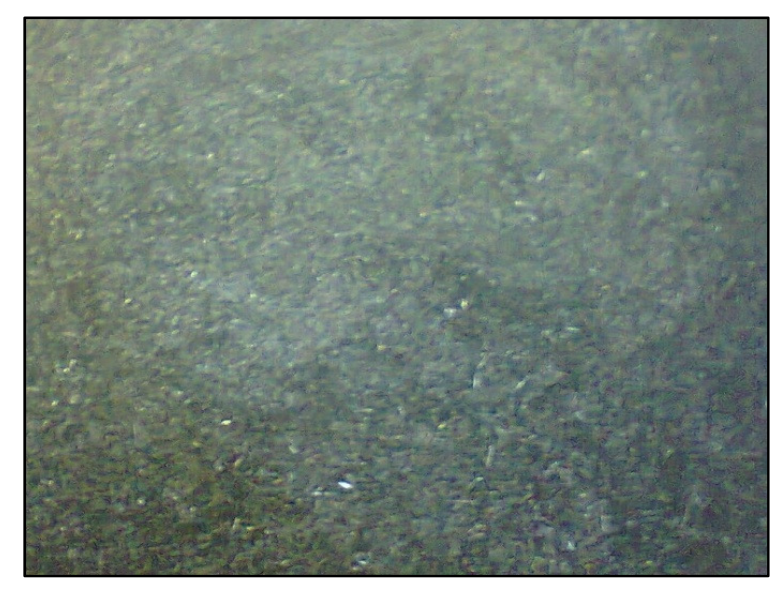

Figura 3: fração de granulometria $<0,3 \mathrm{~mm}$.

- Processo eletroquímico

A partir de soluções sintéticas de $40 \mathrm{~g} / \mathrm{L}$ de cobalto e outras com adição de $2,5 \mathrm{~g} / \mathrm{L}$ de lítio foram realizadas as eletro-obtenções na célula de dois compartimentos com membrana e foram obtidas as seguintes condições ótimas: densidade de corrente de $400 \mathrm{~A} / \mathrm{m}^{2}, \mathrm{pH}=4$ e temperatura de $60^{\circ} \mathrm{C}$, que resultaram em eficiências de corrente acima de $95 \%$ (considerando somente a presença de cobalto).

A composição química e a morfologia de dois depósitos obtidos com as condições ótimas de operação podem ser verificadas nas figuras que seguem: para a solução contendo apenas cobalto, Figura 4 e Figura 6, e para solução contendo cobalto e lítio, Figura 5 e Figura 7.

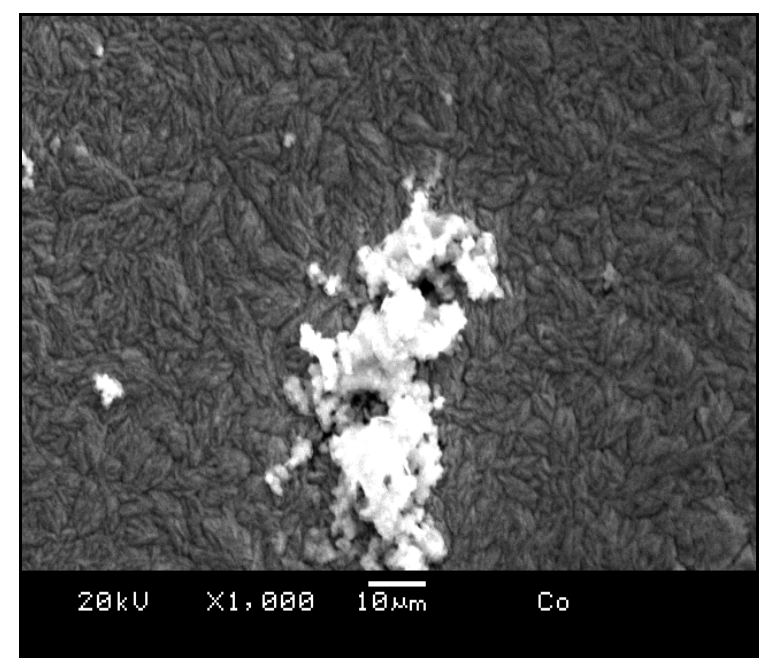

Figura 4: Morfologia de um depósito de $97 \%$ de eficiência de corrente a partir de solução 40g/L de Co. 
Revista Eletrônica em Gestão, Educação e Tecnologia Ambiental

REGET/UFSM (e-ISSN: 2236-1170).

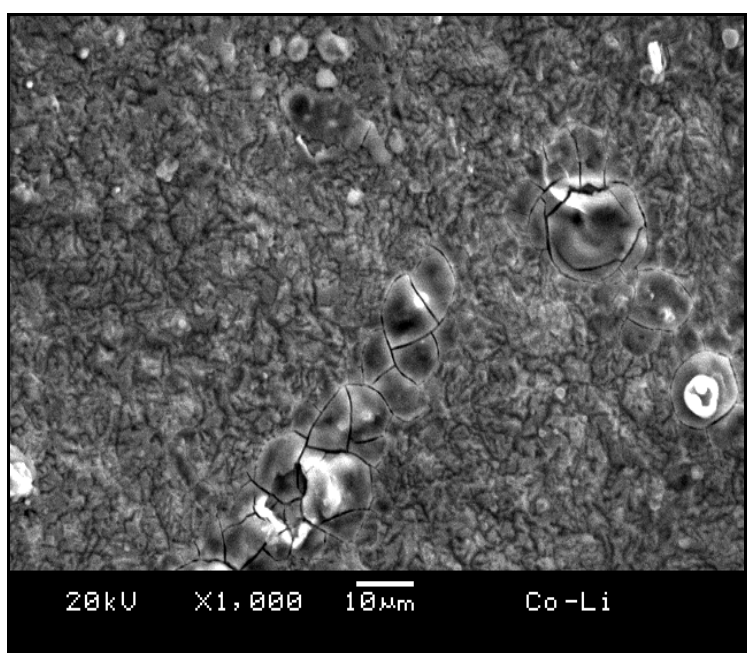

Figura 5: Morfologia de um depósito de $96 \%$ de eficiência de corrente a partir de solução 40g/L de Co e 2,5g/L de Li.

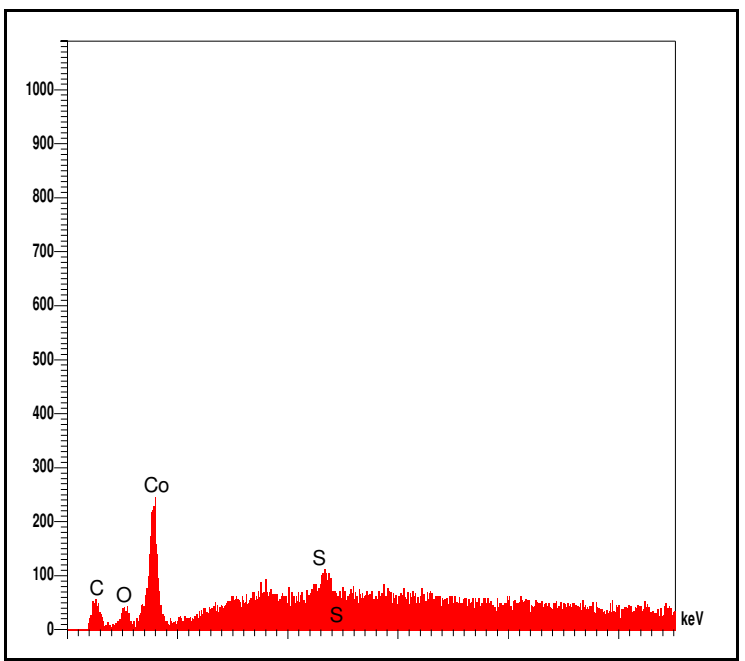

Figura 6: Energia dispersiva de raios-X de um depósito de $97 \%$ de eficiência de corrente a partir de solução $40 \mathrm{~g} / \mathrm{L}$ de Co. 


\section{Revista Eletrônica em Gestão, Educação e Tecnologia Ambiental}

REGET/UFSM (e-ISSN: 2236-1170).

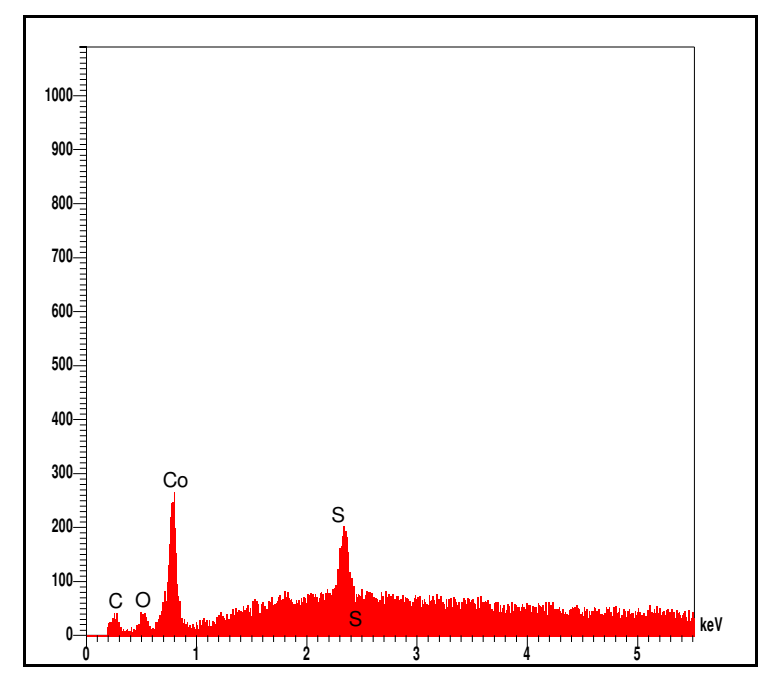

Figura 7: Energia dispersiva de raios-X de um depósito de $96 \%$ de eficiência de corrente a partir de solução $40 \mathrm{~g} / \mathrm{L}$ de Co e de $2,5 \mathrm{~g} / \mathrm{L}$ de Li.

Para investigar se os depósitos eram unicamente formados por cobalto foram realizadas análises por microsonda (EDS), Figura 6 e Figura 7. Nestas análises foi detectado a presença de outros elementos, como oxigênio, enxofre e carbono. A presença de oxigênio provavelmente é devido à formação de hidróxidos. A presença de enxofre está associada, provavelmente com a contaminação pela própria solução em função do caráter poroso do depósito. A presença de carbono, possivelmente esteja relacionada com a fita utilizada para fixar a amostra ao suporte para a realização da análise.

Desta forma, quanto ao teste realizado utilizando uma solução sintética contendo lítio e cobalto, se observou a possibilidade de recuperar o cobalto seletivamente, visto que o lítio não faz parte do depósito (Figura 7).

\section{Conclusões}

Através do tratamento físico e mecânico das baterias conseguiu-se uma boa separação dos compostos existentes na mesma, possibilitando a obtenção de uma fração formada em grande parte de $\mathrm{LiCoO}_{2}$ apropriada para o tratamento químico. Sendo que para uma maior recuperação do Li e Co presentes seria importante a realização de uma nova moagem e separação granulométrica, já que uma quantidade significativa de material ficou retida nas peneiras de maior diâmetro, indicando a possível presença dos metais nessas frações.

As condições de realização da lixiviação da solução real ainda precisam ser avaliadas por técnicas de Espectroscopia de Absorção Atômica, porém qualitativamente pôde-se perceber, devido a coloração avermelhada das soluções resultantes, que cobalto e provavelmente os outros metais foram extraídos das partículas sólidas.

As condições ótimas de operação da eletro-obtenção de cobalto foram determinadas como sendo densidade de corrente de $400 \mathrm{~A} / \mathrm{m}^{2}, \mathrm{pH}=4$ e temperatura de $60^{\circ} \mathrm{C}$, e foram conseguidas através da célula de dois compartimentos e soluções sintéticas. Estas condições foram importantes para se alcançar altas eficiências de corrente, em torno de $95 \%$. A adição de 2,5 g/L lítio não trouxe mudanças significativas na eficiência de corrente nem nas características dos 


\section{Revista Eletrônica em Gestão, Educação e Tecnologia Ambiental \\ REGET/UFSM (e-ISSN: 2236-1170).}

depósitos obtidos. Isso foi comprovado pelas análises dos depósitos das soluções sintéticas (Microscopia Eletrônica de Varredura e Energia Dispersiva de Raios- $\mathrm{X}$ ), devido à ausência de lítio, mesmo quando a solução o continha. O que acaba confirmando a eficiência da eletro-obtenção do cobalto, de forma seletiva.

A presença da membrana aniônica na célula eletroquímica facilitou o controle do $\mathrm{pH}$, podendo ficar por longos períodos sem necessitar de correção. Devido ao pH ficar constante na célula de dois compartimentos foi possível obter depósitos coesos.

Portanto os resultados obtidos neste estudo indicam a viabilidade técnica de recuperação de cobalto por processos físicos e mecânicos de moagem e separação granulométrica, processos químicos de lixiviação e eletroquímicos com célula de dois compartimentos, possibilitando esta recuperação na forma de depósitos sólidos e indicando a necessidade de se realizar, posteriormente, a precipitação seletiva para a recuperação do lítio.

\section{Referências Bibliográficas}

[1] Paulino, J.F.; Busnardo, G.N.; Afonso, J.C.; Recovery of valuable elements from spent li-batteries. Journal of Hazardous Materials 2007, article in press.

[2] Brasil. Política Nacional de Resíduos Sólidos. Lei 12.305 de 2 de Agosto de 2010.

[3] Bernardes, A. M. ; Espinosa, D. C. R; Tenório, J A S. Brazilian policy on battery disposal and its practical effects on battery recycling. Journal of Power Sources, Elsevier, v. 137, p. 134-139, 2004.

[4] Matuano, D.P.; Dorella, G.; Elias, R.C.A.; Mansur, M.B.; Analysis of a hydrometallurgical route to recovery base metals from spent rechargeable batteries by liquid-liquid extraction with cyanex 272 . Journal of Power Sources 159 (2006) 1510-1518.

[5] Shin, M.S.; Kim, N.H.; Sohn, J.S.; Yang, D. H.; Kim, Y.H.; Development of a metal recovery process from liion battery wastes. Hydrometallurgy 79 (2005) 172-181.

[6] Xu, J., H.R. Thomas, R.W. Francis, K.R. Lum, J. Wang and B. Liang; A review of processes and technologies for the recycling of lithium-ion secondary batteries, Journal of Power Sources, 177, 512-527 (2008). 